\title{
Experimental Assessment of PAO and PAG Based Oil Performances in a Screw Compressor
}

\begin{abstract}
RADU MIREA, MIHAIELLA CRETU*
Romanian Research \& Development Institute for Gas Turbines, Bucharest, 220D luliu Maniu Blvd, 061126, Bucharest, Romania

The paper presents comparative results of an experimental assessment for behaviour and performances evolution of poly-alpha-olefin (PAO) and poly-alkyl-glycol (PAG) based oil, used in a natural gas screw compressor. Within such compressor type the oil is directly injected and has simultaneous multiple roles: lubrication, coolant, compressing and sealant. Taking into account the gas composition, the oil type used within the screw compressor directly influences its performances and life span. For a known composition of processed the gas, the PAO and PAG oil was used in the same compressor. Each type of oil has been monitored and specifically analyzed: flash point determination, cinematic viscosity measurement, FTIR analysis for contamination and usage determination. The literature highlights that a thorough monitoring and analyze of the oil is, in fact, one of the most important ways to assess the performances and usage of a screw compressor. Thus, many of the compressor maintenance problems can be identified and solved resulting the increase of its lifespan and decrease of the maintenance expenditures. The data have been centralized and a comparative analysis of PAO and PAG has been made, thus resulting the best solution for the specific problem encountered at the natural gas shaft.
\end{abstract}

Keywords: Poly-alkyl-glycol (PAG), poly-alpha-olefin (PAO), mass spectroscopy, FTIR analysis, flash point, kinematic viscosity

The screw compressor is a positive displacement machine that uses a pair of intermeshing rotors housed in a suitable casing to produce compression. These are capable of high speed operation over a wide range of operating pressures. In screw machines, oil is deliberately injected into the compression chambers to provide sealing, lubrication, corrosion resistance and cooling effect. Screw compressor performance is influenced both by the gas and by the type of used lubricant [1].

In a screw compressor, high gas pressure acts on the rotor helical on surface of helical rotor and hence generates the axial force acting on the male and female rotors. There are also axial forces that act on the rotor discharge and suction end faces [2].

Machine conditioning monitoring or predictive maintenance is a practice of assessing a machine's condition by periodically gathering data on machine-health indicators to determine when to schedule maintenance. Knowing to interpret changing lubricants properties can increase both the uptime and the life of equipment.

Lubricants are the life blood of a gas compressing machinery. As an important element of predictive maintenance technologies, in-service oil analysis, can provide trace information about machinery wear condition, lubricant contamination and as well as lubricant condition. The immediate benefits of in-service oil analysis include avoiding oil mix up, contamination control, condition based maintenance and failure analysis [3] .

There are several types of oil based lubricants and each of them have their advantages and drawbacks. Also there are lots of factors that reduce the effectiveness of lubricants and cause premature wear or damage in rotary screw compressors. The types of lubricants are: mineral oils, synthetic hydrocarbons, organic esters, phosphate esters, poly-glycols, silicones and mixtures based on these mentioned oil types [4].

Mineral oils have been long used in various types of compressors. With oil change intervals as low as every
$1000 \mathrm{~h}$, many manufacturing plants had to change oils eight times per year. An advantage of frequent oil changes is that the contaminants in the compressor are removed with the waste oil. In highly contaminated environments, mineral oil is still used for this reason alone. Mineral oils have the disadvantage of a complex mix of natural hydrocarbon molecules. There are waxes that solidify at low temperatures, volatile components that vaporize and natural mineral oils tend to oxidize quickly forming varnish and sludge, when exposed to high temperatures and elevated pressures [4].

Synthetic hydrocarbon lubricants are engineered for particular applications. For compressor applications, polyalpha-olefin (PAO) based oil is commonly used. PAO provide many of the best lubricating features of a mineral oil and without its drawbacks. Although PAO components are derived from petroleum base stock, they are chemically re-engineered to have a consistent, controlled molecular structure of fully saturated hydrogen and carbon. Because their molecules structure is homogenous, their properties and characteristics are predictable. PAO separate water extremely well, are chemical stabile and have low toxicity. PAOs, however, are not good solvents.

PAGS are commonly used in quenching fluids, metalw orking fluids, gear oils, chain oils, foodgrade lubricants and as lubricants in HFC type hydraulics and gas compressor equipment. Properties that PAGs offer include; high lubricating properties, low traction properties, high viscosity index, controlled quenching speeds, good temperature stability and low wear. They are available in both water soluble and insoluble forms, and in a wide range of viscosity grades [5]. How ever, the water soluble PAGs are incompatible with petroleum oil, and care must be taken in transitioning equipment from hydrocarbon oils to PAGs.

Table 1 shows typical oil analysis parameters and common analytical techniques to monitor machine wear, contamination and degradation. 
Table 1

KEY OIL ANALYSIS PARAMETERS AND CORRESPONDING ANALYTICAL TECHNIQUES [6]

\begin{tabular}{|l|l|l|}
\hline Category & Key analysis & Analytical techniques \\
\hline Machine wear & Fine wear metals & $\begin{array}{l}\text { Rotating disc electrode (RDE), Spectroscopy, } \\
\text { Inductive Coupling Plasma Spectroscopy }\end{array}$ \\
\cline { 2 - 3 } & Large wear metal elements & Rotode filtration Spectroscopy (RFS) \\
\cline { 2 - 3 } & Particle count and distribution & Particle count, LaserNet fine (LNF) \\
\cline { 2 - 3 } & Wear particle shape analysis & LNF, Ferrography, Weea Debris Analysis \\
\hline Contamination & Sand and Dirt & Particle count, LaserNet fine (LNF) \\
\cline { 2 - 3 } & Fuel dilution & Fuel sniffer, Gas Chromatography (GC) \\
\cline { 2 - 3 } & Water/Moisture & Infrared (IR), Karl Fisher titration (KF) \\
\cline { 2 - 3 } & Glycol/Coolant & IR \\
\cline { 2 - 3 } & Soot & Soot meter IR \\
\cline { 2 - 3 } & Alien fluid & IR \\
\hline Degradation & Oxidation, Nitration, Sulfating & IR \\
\cline { 2 - 3 } & Viscosity & Rheoviscosimeter measurements \\
\cline { 2 - 3 } & Acid number/Base number & IR \\
\cline { 2 - 3 } & Flash point & Flash point measurement \\
\hline
\end{tabular}

\section{Experimental part}

The aim of experimental analysis was to test and assess a synthetic lubricant for this particular application, the optimization of compressor's behavior, reduction of the maintenance expenses, increase of the oil change intervals and the reduction of energy consumption of industrial processes in the field of natural gas exploitation.

\section{Method for flash point determination}

Flash point measures the tendency of the sample to form a flammable mixture with air under controlled laboratory conditions. It is the only one of a number of properties which must be considered in assessing the overall flammability hazard of a material. The instrument used for determining flash point of the oils is Automatic Flash Point Tester Cleveland - ASTM D92. The instrument has been manufactured strictly according to the prescriptions reported in the ASTMD92 test method. The test cup is filled to a specific level with the sample. The temperature of the sample is increased rapidly at first and then at a slow constant rate as the flash point is approached. The flash point is the lowest temperature at which application of a test flame causes the vapour above the sample to ignite.

\section{Method for kinematic viscosity determination}

Kinematic viscosity, according to SR EN ISO 3104/2002 standard is experimentally determined by using an Ubbelhode capillary viscometer kept at a constant temperature in a liquid bath. This method consist in measuring of time necessary time for the sample to go through the capillary which has known length and diameter. The kinematic viscosity is determined by multiplying the necessary time (in seconds) with the capillary constant (which is differentfrom one capillary to another). The result of this multiplication gives the kinematic viscosity in $\mathrm{mm}^{2}$ / $\mathrm{s}\left(1 \mathrm{~mm}^{2} / \mathrm{s}=1 \mathrm{cS}\right)$.

\section{FTIR analysis and oil state}

FTIR analysis is a versatile method for detecting usual contaminants, forming of secondary products and degradation of the additives packages or base oils, thus becoming a wide spread technique related to multiple evaluation of oils degradation. The FTIR technique is based on the mathematical operation called Fourier transform and the adsorption lines of the sample are correlated with the ones already known for each type of chemical bond. So, initially a base spectra is measured for a fresh sample of oil. Then, the spectra for the sample is measured and after that, the two spectra are compared and registered differences can provide info related to the changes within oil composition, degradation, contamination and machine wear.

\section{Results and discussions}

The natural gas plant uses screw compressors to compress the natural gas and to send it within the pipes for refining. PAO based oils are usually used within this type of compressors. So, in 4 compressors a PAO based oil was used, Stabio S100. This oil is viscosity class 100, and has a flash point higher than $240{ }^{\circ} \mathrm{C}$. The analysis of the compressed gas shows that it is rich in volatile C3-C7 compounds and consequently experimental PAG based oil PluraSafe CL Gas 9 (PLSF) was used fifth compressor which transport this gas. This oil was specially developed by BASF Germany for this application type (compressing of rich $\mathrm{C}_{3}-\mathrm{C}_{7}$ natural gas). Also, this oil is in viscosity class 100 and has a flash point higher than $290^{\circ} \mathrm{C}$.

\section{Characterization of used oils in experimental analysis}

The characterization methods are in accordance with approved standards and are widely spread along world wide characterization laboratories. Functional characterization of the oils has been done by: flash point and cinematic viscosity determination. Structural characterization was made by FTIR analysis. Within this analysis, anti-wear, oxidation and soot 1980 were determined, each of them giving information about oil degradation and contamination.

\section{Functional characterization by flash point determination}

It was shown that for determining the flash point of oil samples it uses the ASTM D92 method. This method determine the low esttemperature of ignition for a gaseous mixture formed at the surface of a heated liquid. The oil sample was put in an opened cup and slowly heated. In the meantime, an opened flame was used to determine the first ignition of the flammable mixture formed. When the firs ignition appeared, the sample temperature is considered the flash point for the sample. The measurements of flash point showing the state of this parameter during the natural gas compressing, for both oils, are showed in figure 1.

As it can be seen in figure 1 , even tough, each of the two oils have flash point higher than $200^{\circ} \mathrm{C}$, after just few hours, the flash point drops. In the case of Stabio S100 oil, the flash point drops rapidly below $50^{\circ} \mathrm{C}$ and stabilizes there during the lifetime of the oil. The absorption in oils of low volatiles $C_{3}-C_{4}$ from natural gas explains this comportment. In the case of PLSF, the flash point drops and then increases few times, but the average flash point is around $146^{\circ} \mathrm{C}$. Given the fact that, the average working temperature of a 


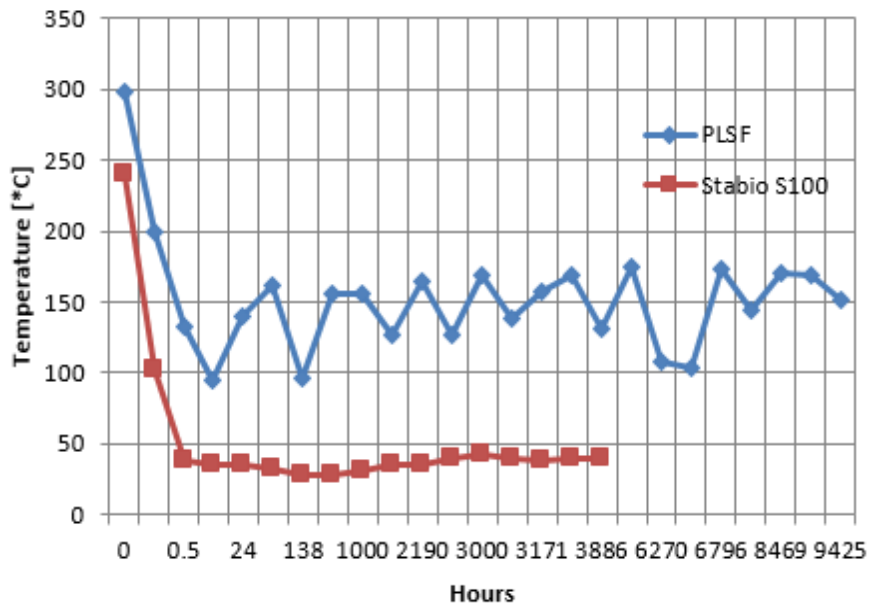

Fig. 1. Flash point dynamics for PLSF and Stabio S100 oils used in a natural gas screw machine

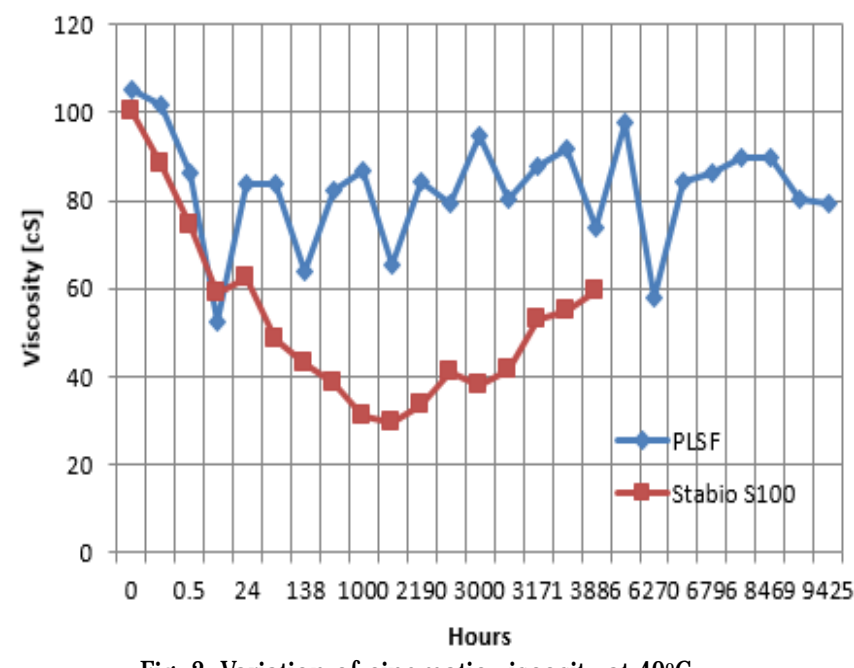

Fig. 2. Variation of cinematic viscosity at $40^{\circ} \mathrm{C}$

screw compressor is around $80^{\circ} \mathrm{C}, \mathrm{PLSF}$ is more suitable to be used in this kind of application.

\section{Functional characterization by kinematic viscosity meassurements}

The method is based on SR EN ISO 3104/2002.. The sample is preheated in a controlled temperature vessel up to $40^{\circ} \mathrm{C}$. After the sample reaches this temperature, a preset quantity is put to get through a capillary having known characteristic, called capillary constant. The necessary time for the sample to get through the capillary is measured and then, multiplied by the capillary constant. The result showing the dynamics of kinematic viscosity (in CS) during the natural gas compressing, for both oils, are showed in figure 2.

As shown in figure 2, the kinematic viscosity of the samples presents important changes in time. Even though, both samples had their cinematic viscosity at $40^{\circ} \mathrm{C}$ about $100 \mathrm{~mm}^{2} / \mathrm{s}$, during their usage, the viscosity decreases. In the case of Stabio S100 oil, the kinematic viscosity drastically drops until $60 \mathrm{~mm}^{2} / \mathrm{s}$ after just 24 working hours. Even more, after about 500 working hours, the kinematic viscosity drops even more to about $26 \mathrm{~mm}^{2} / \mathrm{s}$. Then, the viscosity increses due to the fact that at about 500-700 working hours, $50 \mathrm{~L}$ of fresh oil are added in the compressor. Even so, average value of cinematic viscosity of Stabio S100 oil is $35 \mathrm{~mm}^{2} / \mathrm{s}$. In the case of PLSF oil, after 24 working hours, the cinematic viscosity decreases until $55 \mathrm{~mm}^{2} / \mathrm{s}$, but then increases to more than $80 \mathrm{~mm}^{2} / \mathrm{s}$. This decrease/ increase cycle is repeated trough the entire lifespan of the oil. The average value of PLSF's cinematic viscosity is 82 $\mathrm{mm}^{2} / \mathrm{s}$. The decrease of the kinematic viscosity and flash point are given to the fact that the oil, being in close contact with the natural gas is diluted by the $\mathrm{C} 3-\mathrm{C} 7$ volatile compounds, which at the working pressure of the compressor liquefies. PLSF oil is not compatible with these volatile fractions and they are ejected by this oil. That's why the increases/decreases appear regularly.

\section{Structural characterization by FTIR measurements}

FTIR analysis method can provide information about oil degradation, contamination with new chemical species and the status of its additives complex. This method uses infrared light to measure molecule's bonds vibration and make a prediction of which of them have been modified/ altered during the oil utilization in a screw compressor. First, a sample of fresh oil is measured in order to set a reference spectra. After that, the sample spectra is measured and compared with the reference. The differences are then analyzed using a data base. FTIR analysis of used oil samples provides information about the degradation of the oil by measuring its oxidation, about the contamination of the oil by measuring its sootand about the state of additives complex species by measuring them infrared absorption intensity. All the measurements are based on the radiation absorption method which is then transformed in mathematical function by using Fourier transform. Each of FTIR method results are given in absorbance over $\mathrm{cm}(\mathrm{A} / \mathrm{cm})$. As it is well known, a FTIR apparatus can give much more information than the above mentioned ones, but, for the given application, the three ones above mentioned, are the most significant in order to determine the overall status of oil characteristics. In figures 3,4 and 5 it presents the dynamics of FTIR absorption intensity for characterizing: i) anti-wear oil comportment, ii) oxidation oil comportment and iii) soot oil comportment.

As shown in figure 3, the state of anti-wear additive complex varies during the lifespan of the oils. In the case of Stabio S100 oil, the anti-wear constantly decreases until about 2200 working hours. In the case of PLSF, anti-wear additive has a decrease and then, after 2200 working hours, it increases, having a more constant evolution until about 8500 working hours.

The additive complex of an oil must not be considered as a simple liquor poured in the oil and mixed up. The additives within the complex are chemically bond with base oil molecules. The degradation of additives complex can occur due to the chemical reactions and/or physical mixture of the oil with the volatile compounds from the

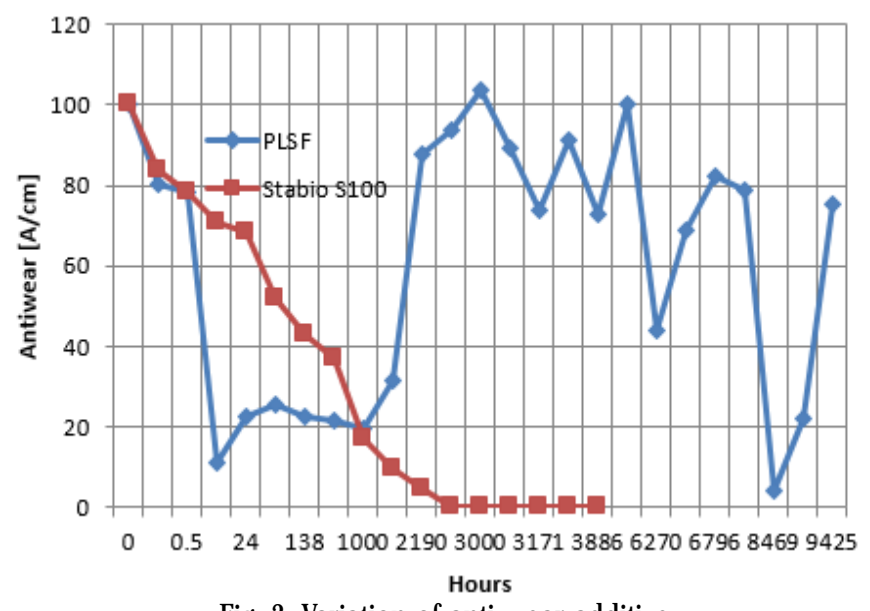

Fig. 3. Variation of anti-wear additive 


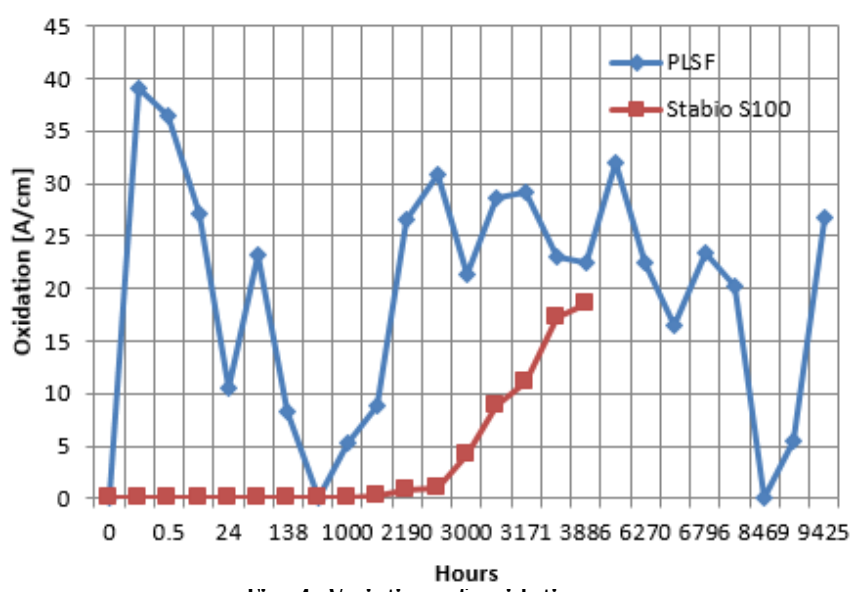

rig. 4. Variation of oxidation

compressed natural gas. Stabio S100 oil, is chemically compatible with C3-C7 liquefied compounds, thus leading to the decrease of anti-wear additive. PLSF is not chemically compatible with C3-C7 liquefied compounds, and then, after a while, these compounds are ejected and anti-wear regains its properties. It was observed that at about 3000 working hours, the anti-wear additive regains its properties and that is due to the ejection of C3-C7 liquefied compounds from oil composition.

The oxidation state of oil is the most important aspect related to its chemical degradation. So a bigger oxidation state of an oil shows a that this oil is degraded. In the case of Stabio S100 oil, the oxidation takes place after 2200 working hours and is closely linked with the consumption of anti-wear and other additives. As it can be seen, until 2200 working hours, the oil is chemically stable, but, after that, the oxidation increases exponentially. In the case of PLSF, the oxidation drastically increases at the beginning of its usage, but, then, it decreases and stabilizes. The oxidation follows the same wave pattern as all the characteristics of this oil.

Soot 1980 determination provides information related to oil contamination with solid particles. The number 1980 represents the wavelength of the radiation characterizing the solid particles presence. While in use, the oil, due to the working temperatures of the compressor, form coke. This coke contaminates the oil an decreases its lubrication and cooling characteristics. As shown in figure 5 , the coke concentration within Stabio S100 started to increase after 2200 working hours, again correlated with the degradation of the oil and its additives complex. In the case of PLSF oil, the coke concentration increases and decreases several times. The wave pattern of the PLSF's behavior is due to the fact that this type of oil was chemically engineered to eject all the physically and chemically bonded impurities every time they reach a preset value/concentration.

\section{Conclusions}

A special type of PAG base oil has been formulated for the specific application where the natural gas to be compressed is very rich in $\mathrm{C} 3-\mathrm{C} 7$ volatile components,

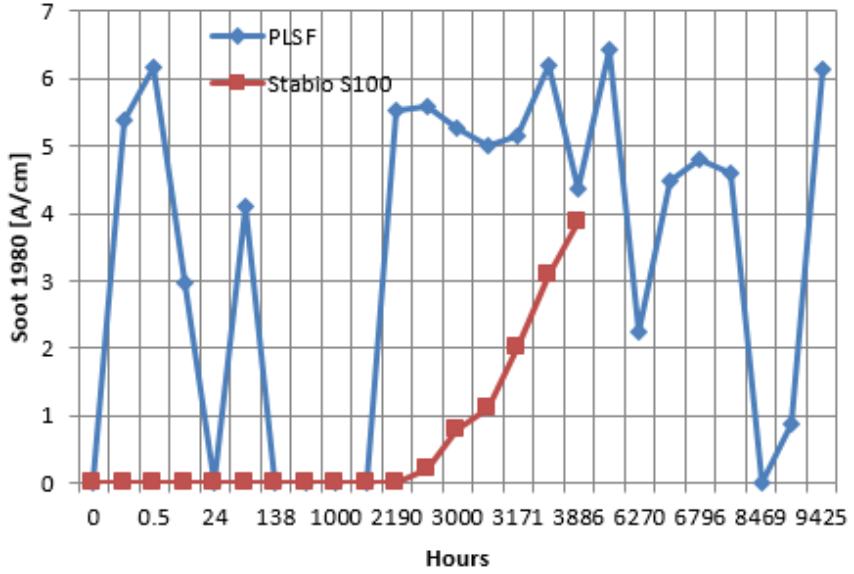

Fig. 5. Variation of soot 1980

which, given the high pressures within the compressor are actually liquefied and have a very bad influence on PAO based oils.

As it can be noticed, the PAO based oil, Stabio S100 has been used for only $3900 \mathrm{~h}$ and then a fresh oil has been put in the compressor; nevertheless, this oil stared to lose its characteristics after $2200 \mathrm{~h}$.

PAG based oil, PLSF has been change after $9200 \mathrm{~h}$ and its main characteristics kept a high average value (cinematic viscosity and flash point). Also, given the application and the nature of the gas to be compressed, this type of oil is chemically stable and is more suitable to be used for compressing rich natural gas.

The main advantages of using this oil are: decrease of losses by oil vaporization, excellent friction coefficient, higher viscosity coefficient, mare stable at compressor's working temperature, low liquefied gas solubility, compressor cleaning effect due to its polarity.

Acknowledgements: The research has been developed within the project no. PN 16.26.06.06/2016, financed by Romanian Research and Innovation Ministry, Bucharest, Romania, programme Nucleu.

\section{References}

1.SESHAIAH N., SAHOO R.K., SARANGI S.K. Theoretical and experimental studies on oil injected screw air compressor when compressing different light and heavy gases, Applied Thermal Engineering, 2010, vol. 30, pp 327-339

2. HOU F., ZHAO Z., YU Z., XING Z. Experimental study of the axial force on the rotors in a screw refrigeration compressor, International J ournal of Refrigeration, vol. 75 (2017), pp 155-163

3. WU X., XING Z., HE Z., WANG X., CHEN W., Effects of lubricating oil on the performance of a semi-hermetic twin screw refrigeration compressor, Applied thermal engineering, vol. 112 (2017), pp 340-351 4.WAYNE P., Basics of rotary screw compressor lubricants, www.kseser.com/whitepapers, Kaeser Compressors, Inc. 877-5862691

5. ${ }^{* * * h t t p s: / / w w w . c r o d a l u b r i c a n t s . c o m / e n-g b / d i s c o v e r y-z o n e / p r o d u c t-~}$ range/polyalkylene-glycol-base-oils

6. ZHAO Y. Oil analysis handbook for predictive equipment maintenance, Spectro Scientific, 2014

Manuscript received: 5.12 .2018 